\title{
Neues Sprecherteam der Jungen Neuroradiologie gewählt
}

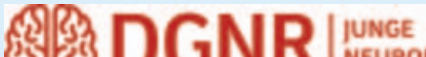

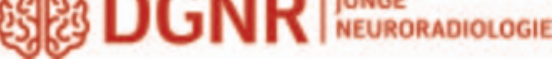

Im Rahmen der 1. Mitgliederversammlung der Jungen Neuroradiologie, die am 5. Oktober 2021 stattgefunden hat, wurde das Sprecherteam der Jungen Neuroradiologie erstmals offiziell gewählt.

\section{Ergebnis der Wahl:}

Wir gratulieren dem neuen Sprecherteam und danken den zahlreichen Bewerberinnen und Bewerbern für ihr Engagement.

Die Junge Neuroradiologie ist eine Gruppierung innerhalb der Deutschen Gesellschaft für Neuroradiologie (DGNR), die im November 2020 ins Leben gerufen wurde. Ziel der Gruppe ist es, sich für die Bedürfnisse von jungen Neuroradiologinnen und -radiologen einzusetzen, um so das spannende Fach für die Zukunft fit zu machen. Bereits über 50 Mitglieder konnten seit der Gründung gewonnen sowie zahlreiche Projekte und Kooperationen auf den Weg gebracht werden. So findet regelmäßig das Kamingespräch „Meet the Expert“ statt, die Vortragsliste „JuNRAD on demand“ sammelt spannende neuroRAD-Vorträge aus den vergangenen Jahren und bietet Kooperationen mit einer Lernplattform sowie einem

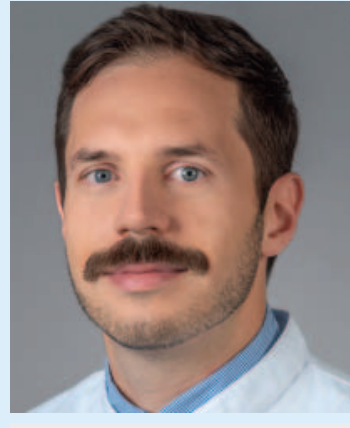

Daniel Kaiser, copyright Universitätsklinikum Carl Gustav Carus Dresden

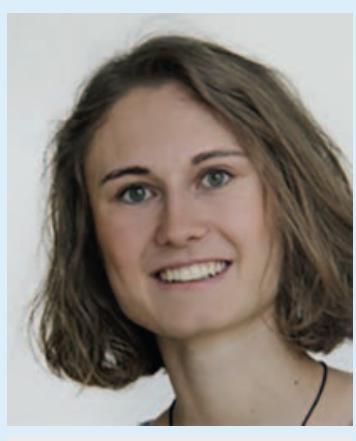

Sarah Schläger

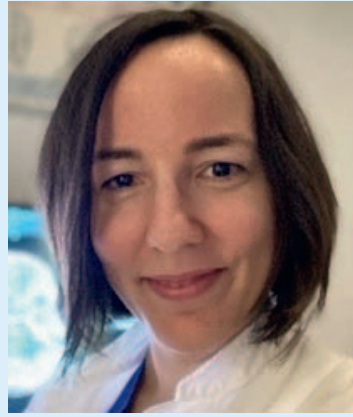

Vivien Richter

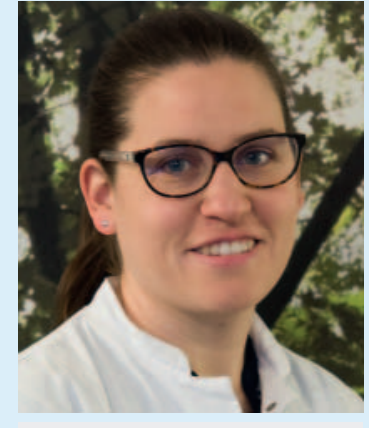

Isabelle Riederer

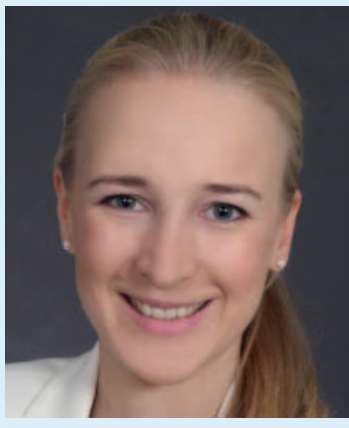

Katharina Schregel
Working Space an, auf die die Mitglieder zugreifen können.
Alle Informationen gibt es hier:
www.junge-neuroradiologie.de. 